\title{
PRODUÇÃO IRRIGADA DE MUDAS DE PIMENTA DEDO DE MOÇA (Capsicum baccatum)
}

Luiz Augusto Dassie, Catariny Cabral Aleman, Ana Carolina Mônico Moreira, Flavia Alessandra Mignacca, Priscila Roberta Leme Zanfolin, Patrícia Reiners Carvalho

Universidade do Oeste Paulista - UNOESTE, Curso de Agronomia, Presidente Prudente, SP. E-mail: patreiners29@gmail.com

\section{RESUMO}

O tamanho da muda de pimenta dedo de moça no momento do transplante para o campo pode determinar sua viabilidade e posterior produtividade. O Objetivo do trabalho foi avaliar o tamanho das mudas de pimenta dedo de moça com relação a diferentes frequências de irrigação. As plântulas foram submetidas a 4 diferentes frequências de irrigação. Os parâmetros biométricos das mudas foram avaliados aos 21 DAS. As mudas submetidas à irrigação na freqüência de 2 vezes ao dia apresentaram tamanho até $6 \%$ superior aos demais tratamentos.

Palavras chaves: eficiência do uso da água; manejo de irrigação; pimenteira.

\section{IRRIGATED PRODUCTION OF PEPPER FINGER SEEDLINGS (Capsicum baccatum)}

\section{ABSTRACT}

The size of the finger pepper molt at the time of transplantation into the field can determine its viability and subsequent productivity. The objective of this work was to evaluate the size of young female finger pepper seedlings in relation to different irrigation frequencies. Seedlings were submitted to 4 different irrigation frequencies. The biometric parameters of the seedlings were evaluated at 21 DAS. The plants submitted to irrigation at the frequency of 2 times a day presented a size up to $6 \%$ higher than the other treatments.

Keywords: efficiency of water use; Irrigation management; peppermint.

\section{INTRODUÇÃO}

As pimenteiras pertencem à família Solanaceae e ao gênero Capsicum. São caracterizadas agronomicamente como cultura olerícola, sendo que a Capsicum baccatum (dedo de moça) está entre as principais espécies cultivadas no Brasil (FILGUEIRA, 2008).

A ampliação do setor nos últimos anos é resultado da agregação de valor ao produto, seja pelo seu processamento na forma de molhos, conservas e geléias ou, ainda, pela desidratação na forma de pó para fabricação de corantes e temperos, dentre outras (CAIXETA et al., 2014).

Dentre as condições de cultivo o manejo da irrigação é fundamental para o desenvolvimento e a produção de pimenteiras, tanto do ponto de vista quantitativo como qualitativo. Na fase de produção de mudas ocorre utilização de água sem definir qual a real necessidade hídrica, isso acarreta desperdício de água e produção de mudas de baixa qualidade.

A necessidade de adequar o suprimento hídrico para o pleno desenvolvimento dos vegetais, decorre das múltiplas funções que ela desempenha na fisiologia das plantas, pois, praticamente todos os processos metabólicos são influenciados pela sua presença. Assim deficiências hídricas iniciais podem afetar sensivelmente 0 processo germinativo comprometendo o estabelecimento da cultura, deficiências posteriores poderão paralisar o crescimento, bem como retardar o desenvolvimento reprodutivo das plantas, assim como o excesso acarreta em prejuízos a cultura com maior incidência de doenças (TAIZ; ZEIGER, 2004).

O objetivo desse trabalho foi avaliar o desenvolvimento de pimenta dedo de moça submetida a diferentes frequências de irrigação. 


\section{MATERIAL E MÉTODOS}

$O$ experimento foi realizado em ambiente protegido no campus II, na Universidade do Oeste Paulista, localizada na Rodovia Raposo Tavares km 572, a uma latitude de $22^{\circ} 07^{\prime} 04^{\prime \prime} \mathrm{S}$ e longitude de $51^{\circ} 22^{\prime} 04^{\prime \prime} \mathrm{W}$, aproximadamente a 432 metros acima do nível do mar. O clima da região é caracterizado, segundo Köppen, como AW mesotérmico, com verões quentes e invernos secos.

As mudas de pimenta dedo de moça (Capsicum baccatum) foram cultivadas a partir de sementes Hortec $^{\circledR}$ em bandejas de isopor com 200 células. Foi utilizado substrato Plantamax ${ }^{\circledR}$ (a base de casca de pínus e vermiculita) para o cultivo das mudas. Essas foram conduzidas até os 21 DAS (dias após a semeadura).

Os tratamentos consistiram em 4 frequências de irrigação: irrigação alternada (dia sim/dia não), irrigação uma vez ao dia (de manhã), irrigação duas vezes ao dia ( de manhã e de tarde) e irrigação três vezes ao dia (de manhã, no meio do dia e de tarde). O início da aplicação dos tratamentos ocorreu após emergência de $90 \%$ das plantas, aproximadamente com 7 DAS.

As lâminas de irrigação foram calculadas de acordo com a evapotranspiração de referência (ETO) mensal. A ETO foi determinada de acordo com a metodologia de Penman-Monteith do
FAO-56 (ALLEN et al., 1998). Após calculada a ETO, essa foi aplicada com auxílio de proveta milimetrada e regador, e fracionada de acordo com os tratamentos de frequência de irrigação. Foi considerada uma lâmina de irrigação média diária de 7,41 mm.

O delineamento experimental foi inteiramente casualizado com 4 frequências de irrigação e 5 repetições, totalizando 20 unidades experimentais. Em cada bandeja foram selecionados aleatoriamente 50 plantas..

Os parâmetros avaliados foram altura de plantas (a cada 7 dias); número de folhas comprimento de raiz, massa seca de parte aérea e raiz.

Os parâmetros foram observados aos 21 DAS, os dados foram submetidos a análise de variância e ao Teste Tukey ao nível de significância de $5 \%$ para comparação de médias. Para essas avaliações estatísticas foi utilizado o pacote estatístico Assistat.

\section{RESULTADOS E DISCUSSÃO}

Foi possível observar que as diferentes frequências de irrigação resultaram no efeito significativo na altura de planta. Para as outras variáveis analisadas não houve efeito significativo para as frequências de irrigação testadas (Tabela $1)$.

Tabela 1. Valores de F para os parâmetros avaliados da pimenta dedo de moça submetida a diferentes frequências de irrigação.

\begin{tabular}{cc}
\hline FV & Freqüência de irrigação \\
\hline Alt. & $3,451^{*}$ \\
NF & $1,025^{\mathrm{ns}}$ \\
CR & $0,251^{\mathrm{ns}}$ \\
MSPA & $0,797^{\mathrm{ns}}$ \\
MSR & $1,162^{\mathrm{ns}}$ \\
R/PA & $0,222^{\text {ns }}$
\end{tabular}

Onde: Alt é a altura das plantas (cm), NF é o número de folhas, CR é o comprimento da raiz (cm), MSPA é a massa seca de parte aérea $(\mathrm{g}), \mathrm{MSR}$ é a massa seca de raiz $(\mathrm{g})$ e R/PA é a relação raiz/parte aérea. Os valores de $\mathrm{F}$ com *= significância a $5 \%$, e n.s.= não significativo.

Na tabela 2 foi possível verificar que para a altura de plantas a frequência de irrigação de 2 vezes ao dia resultou no maior crescimento das mudas. 
Tabela 2. Parâmetros biométricos de mudas de pimenta avaliados aos 21 DAP.

\begin{tabular}{cccccc}
\hline Tratamentos & $\begin{array}{c}\text { Comprimento } \\
\text { de raiz }(\mathrm{cm})\end{array}$ & $\begin{array}{c}\text { Massa seca de } \\
\text { raiz }(\mathrm{g})\end{array}$ & $\begin{array}{c}\text { Número de } \\
\text { folhas }\end{array}$ & $\begin{array}{c}\text { Massa seca de parte } \\
\text { aérea (g) }\end{array}$ & $\begin{array}{c}\text { Altura de } \\
\text { plantas }(\mathrm{cm})\end{array}$ \\
\hline Alternado & $6,2 \mathrm{a}$ & $0,0370 \mathrm{a}$ & $4,3 \mathrm{a}$ & $0,0143 \mathrm{a}$ & $5,6 \mathrm{~b}$ \\
1 vez & $6,9 \mathrm{a}$ & $0,0342 \mathrm{a}$ & $4,6 \mathrm{a}$ & $0,0155 \mathrm{a}$ & $5,6 \mathrm{~b}$ \\
2 vezes & $6,7 \mathrm{a}$ & $0,0321 \mathrm{a}$ & $4,3 \mathrm{a}$ & $0,0151 \mathrm{a}$ & $6,0 \mathrm{a}$ \\
3 vezes & $7,2 \mathrm{a}$ & $0,0515 \mathrm{a}$ & $4,3 \mathrm{a}$ & $0,0175 \mathrm{a}$ & $5,8 \mathrm{~b}$ \\
\hline dms & 1,32 & 0,03 & 0,55 & 0,08 & 0,46 \\
CV\% & 10,88 & 40,07 & 6,99 & 30,31 & 4,4 \\
\hline
\end{tabular}

Médias seguidas pela mesma letra na coluna não diferem entre si pelo teste Tukey a $5 \%$ de probabilidade.

Fatores como número de folhas e altura de plantas são utilizados como base para o transplante de mudas para o campo. De acordo com Bosland e Votava (1999) e Ribeiro et al. (2008), o transplante para o local definitivo de mudas de pimenta deve ser realizado entre 30 e 40 dias após a semeadura, já que nesse período as mudas apresentam 3 a 4 pares de folhas verdadeiras e aproximadamente 10 a $12 \mathrm{~cm}$ de altura.

Embora o número de folhas das mudas de pimenta dedo de moça não tenham se diferenciado significativamente, aos 21 dias após semeadura já apresentavam 2 pares de folhas,o que pode acreditar que aos 30 ou 40 dias após a semeadura cheguem nos 3 a 4 pares de folhas (Tabela 2).

Outro fator importante é a altura das mudas, já que mudas com baixo desenvolvimento podem ser afetadas com o transplante, prejudicando o dossel final e a produção.

A freqüência que apresentou maior altura de plantas foi a irrigada duas vezes ao dia, comparada com as demais avaliadas. Também aos 21 dias após a semeadura teve altura próxima a esperada, com $6 \mathrm{~cm}$, o que indica que aos 30 a 40 dias após a semeadura chegue a uma altura de 10 a $12 \mathrm{~cm}$ (BOSLAND; VOTAVA, 1999; RIBEIRO et al., 2008) (Tabela 2).

Silva et al. (2012) também obtiveram maior altura de mudas para Mezilaurus itauba, Lafoensia glyptocarpa e Leucaena leucocephala quando irrigadas 2 vezes ao dia.

Segundo Silva (2009) a idéia básica do manejo de irrigação é proporcionar benefícios, desde que as plantas sejam supridas com água na hora e quantidade adequada. A decisão correta não é uma tarefa fácil, sendo que tem duas questões a ser consideradas que é quando e quanto irrigar. Tendo para isso que ter experiência com o uso da irrigação e conhecimentos do solo, clima e cultura, assim como do método de irrigação.

Conforme Marouelli et al. (2011) existem vários indicadores de manejo podendo ser agrupados e baseados na planta, no solo ou na atmosfera (evapotranspiração). $O$ indicador baseado no solo geralmente fornece informações de quando e o quanto irrigar em contrapartida o indicador baseado na planta apenas permite estabelecer quando irrigar e os baseados na atmosfera estimam-se apenas a quantidade de água a ser utilizada. Sendo que na prática geralmente é utilizado mais de um indicador do sistema solo-planta-atmosfera, para o manejo de irrigação.

Em relação à produção das mudas, a quantificação da necessidade hídrica na sua formação é extremamente importante, pois a falta ou excesso pode limitar o desenvolvimento das mesmas. A falta de água leva ao estresse hídrico (desejável somente na rustificação), além da diminuição na absorção de nutrientes. O excesso pode favorecer a lixiviação dos nutrientes e também proporcionar um microclima favorável ao desenvolvimento de doenças, além das questões socioambientais relativas à economia de água e o acúmulo de lixiviados no solo (LOPES et al., 2005).

Nesse caso, podemos observar que as frequências aplicadas menores e maiores do que 2 vezes ao dia obtiveram altura de mudas semelhantes (Tabela 2), fato que pode ser explicado pela sensibilidade de plântulas ao excesso de água, que pode diminuir os níveis de Oxigênio no solo acarretaram efeitos semelhantes aos do estresse hídrico.

Como a necessidade hídrica varia entre as espécies, e ao longo do seu ciclo, conhecer as respostas das espécies é de grande importância para a elaboração de planos de manejo adequados, considerando-se o uso racional dos recursos disponíveis, de maneira a se obter 
rendimentos econômicos mais altos (MONTEIRO et al., 2006, LIMA et al., 2012).

\section{CONCLUSÃO}

O manejo de irrigação duas vezes ao dia aumenta em até $6 \%$ o tamanho das mudas de pimenta dedo de moça para posterior transplante.

\section{REFERÊNCIAS}

BOSLAND, P. W.; VOTAVA, E. J. Peppers: vegetable and spice Capsicums. New York: $C A B I$, 1999. 204p.

CAIXETA, F.; VON PINHO, E. V.R.; GUIMARÃES, R.M.; PEREIRA, P.H.A.R.; CATÃO, H.C.R.M. Physiological and biochemi-cal alterations during germination and storage of habanero pepper seeds. African Journal of Agricultural Research, v. $9, \quad$ n. $6, \quad$ p. $627-635,2014$. https://doi.org/10.5897/AJAR2013.7133

FILGUEIRA, F. A. R. Novo manual de olericultura: agrotecnologia moderna na produção e comercialização de hortaliças. Viçosa: UFV, 2008. 421p.

LIMA, M.E.; CARVALHO, D.F.; SOUZA, A.P.; ROCHA, H.S.; GUERRA, J.G.M. Desempenho do cultivo da berinjela em plantio direto submetida a diferentes lâminas de irrigação. Revista Brasileira de Engenharia Agrícola e Ambiental, v. 16, n. 6, p. 604-610, 2012. https://doi.org/10.1590/S1415$\underline{43662012000600003}$

LOPES, J.L.W.; GUERRINI, I.A.; SAAD, J.C.C.; SILVA, $M$. Efeitos da irrigação na sobrevivência, transpiração e no teor relativo de água na folha em mudas de Eucalyptus grandis em diferentes substratos. Scientia forestalis, n. 68, p. 97-106, 2005.

MAROUELLI, W. A.; OLIVEIRA, A. S.; COELHO, E. F.; NOGUEIRA, L. C.; SOUSA, V. F. Manejo da água de irrigação. In: SOUSA, V.F.; MARQUELLI, W.A.; COELHO, E.F.; PINTO, J.M.; COELHO FILHO, M.A. Irrigação e fertirrigação em fruteiras e hortaliças. Brasilia: Embrapa Informação Tecnológica, 2011. Cap. 5, p.158-232.

MONTEIRO, R.O.C.; COLARES, D.S.; COSTA, R.N.T.; LEÃO, M.C.S.; AGUIAR, J.V. Função de resposta do meloeiro a diferentes lâminas de irrigação e doses de nitrogênio. Horticultura Brasileira, v.
24, n. 4, p. 455-459, 2006. https://doi.org/10.1590/S0102$\underline{05362006000400012}$

RIBEIRO, C.S.C.; LOPES, C.A.; CARVALHO, S.I.C.; HENZ, G.P.; REIFSCHNEIDER, F.J.B. Pimentas Capsicum. Brasília: Embrapa Hortaliças, 2008. $200 p$

SILVA, A.A.G. Material didático para o curso prático de agrometeorologia aplicado à otimização do uso da água na irrigação. Aracaju: EMBRAPA Tabuleiros Costeiros, 2009. 103 p. (Documentos/ Embrapa Tabuleiros Costeiros; 155)

SILVA, C.C.; MARCHINI, J.; GRANELLA, S.J.; SOUZA, A.P.; SILVA, A.C. influencia da frequencia de irrigação no crescimento inicial de mezilaurus itauba, lafoensia glyptocarpa e leucaena leucocephala. In: CONGRESSO FLORESTAL PARANAENSE, Paraná, 4. Anais... 2012.

TAIZ, L.; ZEIGER, E. Fisiologia vegetal. 3. ed. Porto Alegre: Artmed, 2004.

Recebido para publicação em 21/06/2017

Revisado em 06/11/2017

Aceito em 18/11/2017 